\title{
Assessment of Different Manifestations of Known Cases of Behçet's Disease
}

\author{
Fatemeh Owlia $^{1}$ (D), Zahra Khodaei-Ardakani ${ }^{2 *}$ (D), Hosein Soleimanisaleh-Abadi ${ }^{3}$ iD \\ 1. Dept. of Oral and Maxillofacial Medicine, School of Dentistry, Shahid Sadoughi University of Medical Sciences, Yazd, Iran \\ 2. School of Dentistry, Shahid Sadoughi University of Medical Sciences, Yazd, Iran \\ 3. Dept. of Rheumatology, School of Medicine, Shahid Sadoughi University of Medical Sciences, Yazd, Iran
}

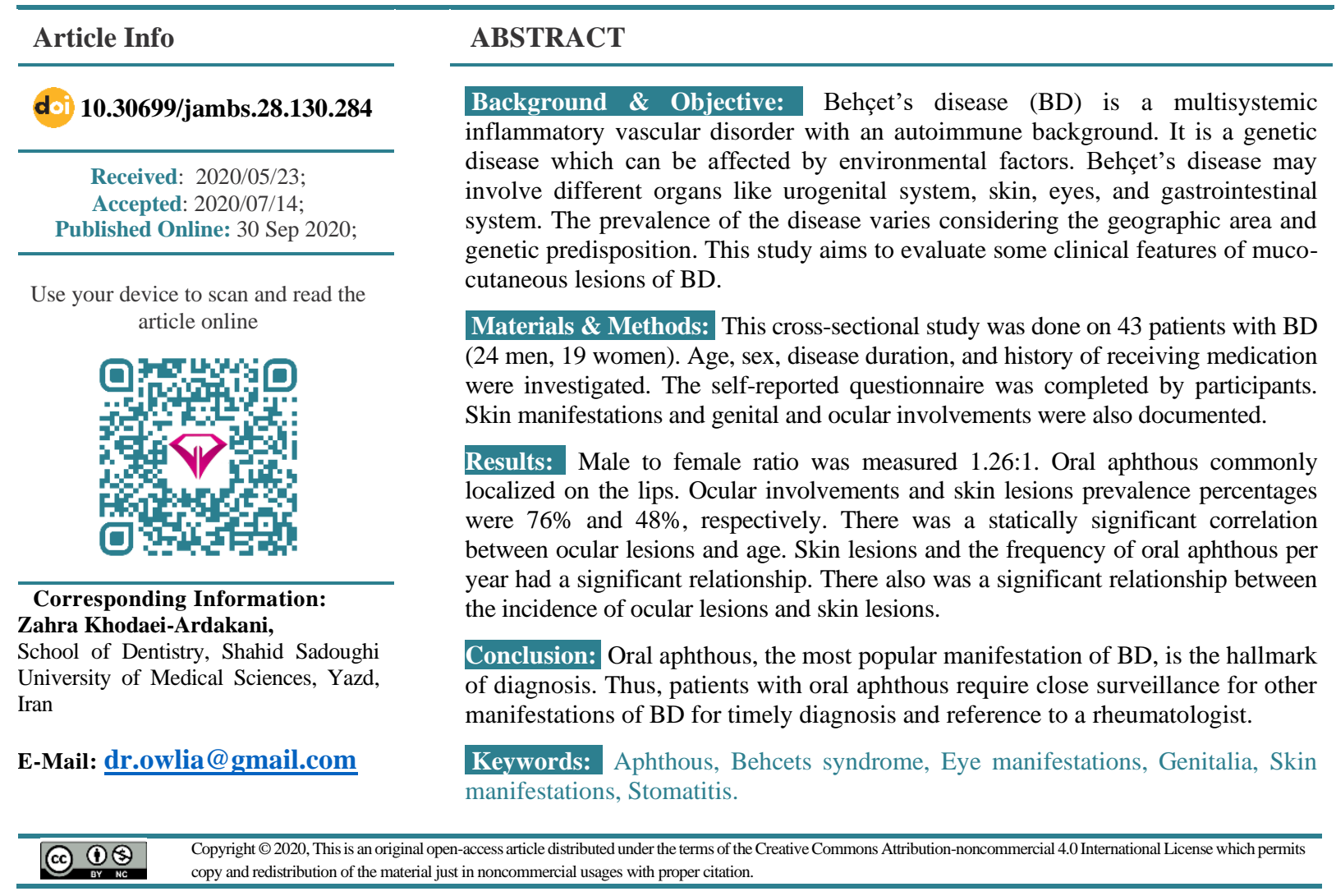

\section{Introduction}

Behçet's disease (BD) is a chronic vascular immunemediated disease. The etiology of the disease is not completely recognized (1-8). BD can be found anywhere throughout the world; however, it is more prevalent in countries along the ancient Silk Road such as Turkey, Iran, Iraq, and Japan. The pattern of BD depends on race $(1,3,4)$. Initially published in 1937 , BD criteria included triad signs: recurrent oral aphthous, genital ulcer, and ocular involvement (1-3, 6, 9-11). Strong association of BD with HLA-B51 has been confirmed in many different ethnic groups from the Middle East to the Far East, and about $40-80 \%$ of mentioned patients possess HLA-B5 or B51 (12-16).

$\mathrm{BD}$ is a multisystemic disease with prominent manifestation of oral aphthous. This finding usually appears as the first symptom, followed by genital ulcers, skin lesions and ocular involvement (1-8).

Sometimes, BD is accompanied by arthralgia, arthritis, intestinal ulceration and CNS complications (1).
The most recent international criteria for BD were approved in 2006 in which scoring four points or more was strongly suggestive of BD. Each of oral, ocular and genital ulcers were allocated two points while skin lesions, neurologic, and vascular manifestations had a score of one. Despite being optional, a positive pathergy test also has a score of one $(6,8)$.

According to the recent criteria, oral aphthous ulcers are considered the main components of the disease (1-4, 10, 17-20). The first BD symptom is usually observed when patients are in their 30 s or 40 s. The sooner the disease begins, the more severe the disease will be, and the longer it will take to recover $(1-4,6,10,18-22)$. Behçet's disease manifestation differs between races and sexes $(\mathbf{1}, 5,23,24)$. In Middle East, men are more susceptible in contrast to Japan and Korea (1, 2, 25-27).

\section{Materials and Methods}

A total of 43 consecutive BD patients composed of 24 males and 19 females took part in this study. They 
were followed at a private rheumatologic clinic and met the inclusion criteria. They were included in the study from July to November 2018. All patients agreed to participate in the study and signed a letter of informed consent. After gathering a comprehensive history, participants' data were collected. Mentioned data included patients' age, sex, disease duration, and history of receiving medication. The questionnaires were completed by the participants themselves. They were asked about the clinical characteristics of the disease (number, location, and size of oral ulcers). Skin manifestations and genital and ocular involvement were also documented. After filling out the questionnaire, an oral examination was performed by a trained senior dentistry student to determine each participant's oral health status.

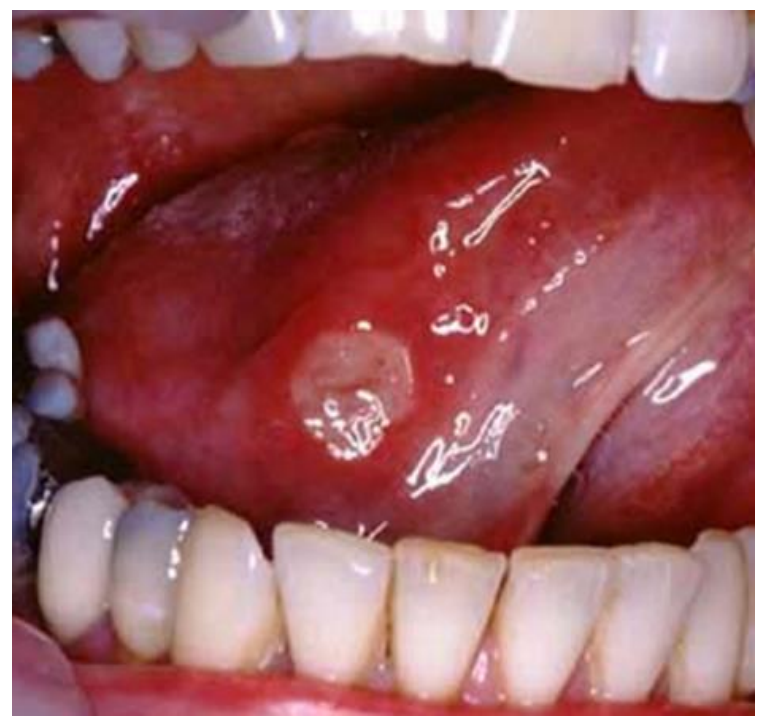

The inclusion criteria were as follows: Regular visits by the related specialist, having a complete medical document, and disease duration of more than one year. Patients with poor oral hygiene, tobacco use, or a simultaneous disease with a probable manifestation of aphthous ulcers (e.g. anemia, celiac, or inflammatory bowel disease) were excluded from the study.

Our study was approved by the ethics committee of Yazd Shahid Sadoughi University of medical sciences (IR.SSU.REC.13970037).

The obtained data were analyzed using SPSS 17. The chi-square and Fisher exact tests were used. Differences were defined as statistically significant at $P<0.05$.

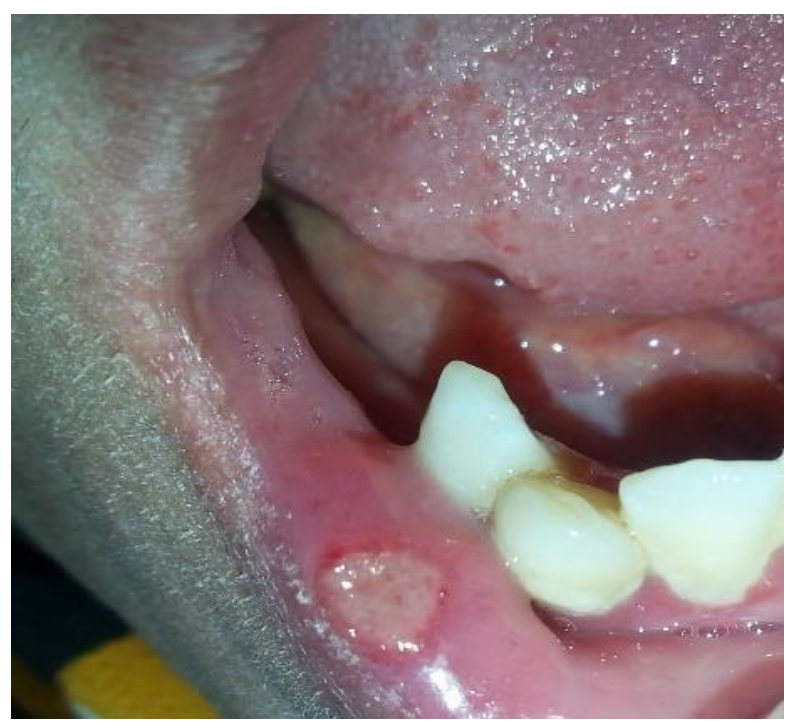

Figure 1. Oral and labial manifestations of BD patients
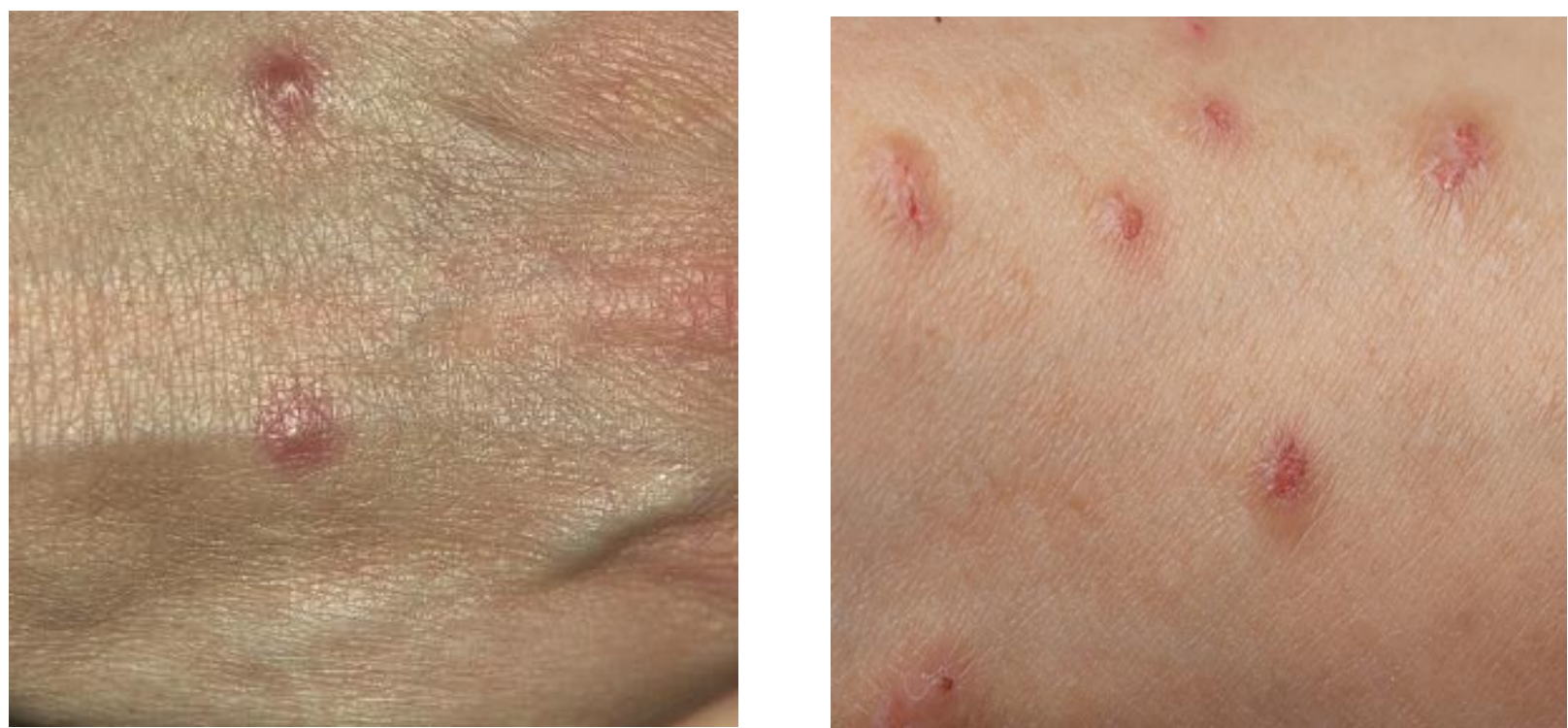

Figure 2. Skin involvement in BD patient 


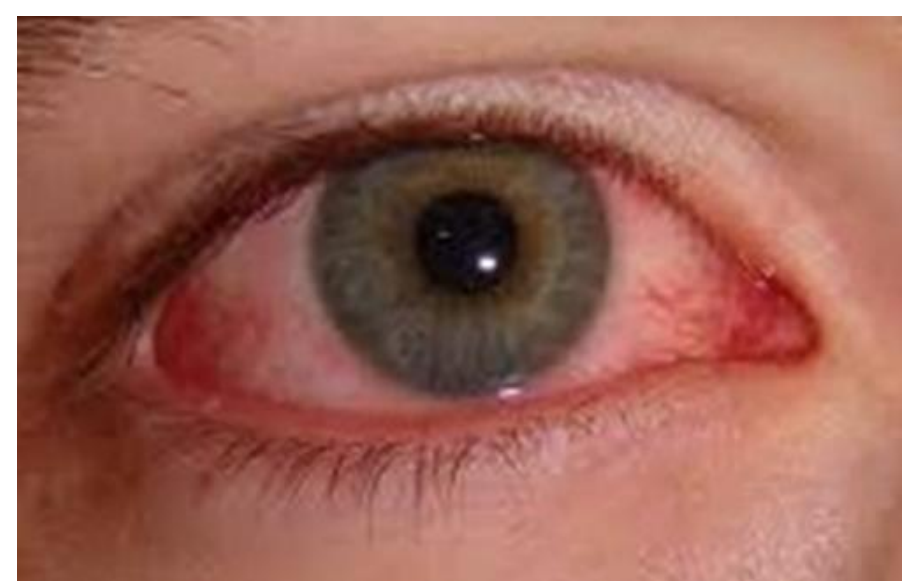

Figure 3. Eye involvement in BD patient

\section{Results}

Men accounted for 24 of the 43 study patients, and women accounted for 19 . The male to female ratio was determined to be 1.26:1. Patients' ages ranged from 19 to 64 years. BD was mostly prevalent among the $40-49$ age group $(39.5 \%)$ and least common in participants who were under $30(4.7 \%)$. Oral aphthous were evident in $100 \%$ of patients. They were commonly localized on the lips (46.5\%) and buccal mucosa (37.2\%). It occurred two to five times per year in 16 patients $(37.2 \%)$, less than twice per year in 16 patients (37.2\%), and more than five times per year in 11 patients $(25.6 \%)$. When family history was evaluated, six $(13.9 \%)$ patients had a positive history of BD in their family, and the others had either a negative or an unknown history. Previous genital ulcers were determined in 28 patients $(65 \%)$. Ocular involvement and skin lesions were reported in $76 \%$ and $48 \%$ of the patients, respectively (Table 1).

Table 1. Some clinical features of the patients with BD

\begin{tabular}{|c|c|c|c|}
\hline Variable data & classification & number & $\%$ \\
\hline \multirow{3}{*}{ Duration of disease } & $<1$ year & 0 & 0 \\
\hline & $1-5$ year & 1 & 2.3 \\
\hline & $>5$ year & 42 & 97.7 \\
\hline \multirow{2}{*}{ Familial history } & yes & 6 & 14 \\
\hline & no & 37 & 86 \\
\hline \multirow{3}{*}{$\begin{array}{l}\text { Incidence of oral aphthous } \\
\text { lesion per year }\end{array}$} & $<2$ & 16 & 37.2 \\
\hline & $2-5$ & 16 & 37.2 \\
\hline & $>5$ & 11 & 25.6 \\
\hline \multirow{4}{*}{ location } & Lip & 20 & 46.5 \\
\hline & Sublingual & 6 & 14 \\
\hline & Floor of mouth & 1 & 2.3 \\
\hline & cheek & 16 & 37.2 \\
\hline \multirow{2}{*}{ Genital involvement } & Yes & 28 & 65.1 \\
\hline & No & 15 & 34.9 \\
\hline \multirow{2}{*}{ Ocular involvement } & Yes & 33 & 76.7 \\
\hline & No & 10 & 23.3 \\
\hline \multirow{2}{*}{ Skin involvement } & Yes & 21 & 48.8 \\
\hline & No & 22 & 51.2 \\
\hline
\end{tabular}


There was a statistically significant relationship between skin lesions and the incidence of oral aphthous ulcers per year $(P=0.049)$ (Table 2) (Figures 1 and 2).

Patients with more frequent oral aphthous had more skin lesions. Also, ocular involvement tended to occur more frequently in patients older than 50 years $(P=0.038)$. More than half of the patients dealt with ocular and genital involvements $(76 \%$ and $65 \%$, respectively). Skin lesions were observed in 21 patients (48.8\%) (Table 3).

Table 2. Correlation between skin involvement and frequency of oral aphthous per year

\begin{tabular}{ccc} 
frequency of oral aphthous per year & \multicolumn{2}{c}{ Skin involvement } \\
& Yes N $(\%)$ & No N $(\%)$ \\
$2-5$ & $6(37.5)$ & $10(62.5)$ \\
$>5$ & $6(37.5)$ & $10(62.5)$ \\
\hline
\end{tabular}

Table 3. Correlation between clinical manifestations and age

\begin{tabular}{|c|c|c|c|c|c|c|}
\hline \multirow{2}{*}{$\begin{array}{c}\text { age } \\
\text { manifestations }\end{array}$} & & $<30$ & $30-39$ & $40-49$ & $>50$ & \multirow{2}{*}{$P$ value } \\
\hline & & $\mathrm{N}(\%)$ & $\mathrm{N}(\%)$ & $\mathrm{N}(\%)$ & $\mathrm{N}(\%)$ & \\
\hline \multirow{2}{*}{ ocular } & Yes & $1(50)$ & $7(58.3)$ & $14(82.4)$ & 11(91.7) & \multirow{2}{*}{0.038} \\
\hline & No & $1(50)$ & $5(41.7)$ & $3(17.6)$ & $1(8.3)$ & \\
\hline \multirow{2}{*}{ skin } & Yes & $1(50)$ & $5(41.7)$ & $9(52.9)$ & $6(50)$ & \multirow{2}{*}{0.961} \\
\hline & No & $1(50)$ & $7(58.3)$ & $8(47.1)$ & $6(50)$ & \\
\hline \multirow{2}{*}{ genital } & Yes & $1(50)$ & $10(83.3)$ & $11(64.7)$ & $6(50)$ & \multirow{2}{*}{0.367} \\
\hline & no & $1(50)$ & $2(16.7)$ & $6(35.3)$ & $6(50)$ & \\
\hline
\end{tabular}

Table 4. Correlation between skin lesions and ocular involvement.

\begin{tabular}{cccc} 
& \multicolumn{2}{c}{ Skin involvement } & Total \\
Ocular involvement & Yes & No $(\%)$ \\
& $\mathrm{N}(\%)$ & $\mathrm{N}(\%)$ & $33(100)$ \\
\hline Yes & $13(39.4)$ & $20(60.6)$ & $10(100)$ \\
\hline
\end{tabular}

Frequency of skin lesions and genital involvement did not increase with age.

Even though there was no statistically significant relationship between skin lesions and genital involvement, the relationship between ocular involvement and skin lesions was significant. $(P=0.034)$ (Table 4).

\section{Discussion}

Many studies have been conducted about the clinical features of BD in different countries. Due to the potent role of genetics, its manifestation could vary across different geographic areas and ethnic groups.
Therefore, occasional evaluation of BD characteristics is of great importance even in the same country. Although the small sample size of this study was one of its limitations, the strict inclusion criteria were applied to increase its accuracy. In this cross-sectional study, the occurrence of some clinical manifestations of BD was evaluated in an Iranian population. Despite the limited population, this study is valuable since no previous study has examined the clinical features of BD in Yazd from a comprehensive point of view.

A notable advantage in the present study was ruling out systemic diseases related to oral aphthous. This led to more reliable results in comparison with previous studies. The male to female ratio was $1.26 / 1$. The predilection for male involvement is similar to reports 
by Davari (9) and Lennokove (23) but different than California, US-based studies $(28,29)$.

Regarding the inclusion criteria, BD patients with a disease duration of at least one year were included in the study. Oral aphthous ulcers were seen in $100 \%$ of patients, indicating that this is a hallmark of $\mathrm{BD}$, independent of patient demographics. It occurred more than five times per year in $25.6 \%$ of patients. The importance of family history is supported in the literature (23). The occurrence frequency of oral aphthous in the families was $14 \%$. This is close to the proportion detected in the analysis of Ugurlu et al. (30); however, this percentage is lower than the percentages reported in some previous studies $(31,32)$. This low percentage may be due to the lack of knowledge about family involvement among some patients.

Some studies ignored the location of oral aphthous ulcers $(1,23,31)$. In this study, oral aphthous was mostly seen on the lips, followed by buccal mucosa and tongue, respectively. This finding was in accordance with the results of Alposy (2) and Cansu (31), who stated that the tongue was the most common involved location (31).

Genital ulcers were found in 28 patients $(65.1 \%)$ These results are in line with studies by Davatchi and Sula $(1,33)$, who reported involvement rates of $64.4 \%$ in Iran and $70 \%$ in Turkey. These percentages are less than what Lennikoves reported in Russia (23). These differences could be attributed to special HLA in some races. It is worth mentioning that the results may be underestimated due to the shame, fear, or disregard of patients (33).

The frequency of ocular involvement in this study was $76.7 \%$. This ratio was higher than what was reported in previous studies in Iran and Turkey $(1,33)$. This may be attributed to the warm and dry weather of geographic area of the study. Another reason could be the higher incidence of ocular involvement in men in this study (5). This finding is consistent with the Sula's findings, who reported the disease to be more common in males and young patients (33).

Many of our patients were referred by ophthalmologists, and they were diagnosed based on ocular involvement in the advanced stage of BD. There was a statistically significant relationship between age and ocular involvement. Ocular involvement would increase with aging (33). Regarding the high frequency of ocular involvement in the BD patients, ophthalmologic consultations should be considered annually. These results indicated that the frequency of oral aphthous can be used as a severity index for BD. This was concluded because of the significant relationship between skin lesions and the frequency of oral aphthous per year. The more severe the disease, the higher the possibility of involvement of organs in the course of the disease.

\section{Conclusion}

Oral aphthous, the most widespread manifestation of $\mathrm{BD}$, is the hallmark of $\mathrm{BD}$ diagnosis. Thus, patients with oral aphthous require close surveillance for other manifestations of BD. Timely diagnosis and reference to Rheumatologists improves patients' quality of life. Ocular lesions can be affected by age. There was a positive association between skin lesions and ocular involvement.

\section{Ethical considerations}

Ethical issues (Including plagiarism, informed consent, misconduct, data fabrication and/or falsification, double publication and/or submission, redundancy, etc.) have been completely observed by the authors.

\section{Acknowledgments}

This study has been financially supported by Yazd Shahid Sadoughi University of Medical Sciences Vice Chancellor for Research and Technology.

\section{Conflict of Interest}

Authors declared no conflict of interest.

\section{References}

1. Davatchi F, Chams-Davatchi C, Shams H, et al. Behcet's disease: epidemiology, clinical manifestations, and diagnosis. Expert Rev ClinImmunol. 2017;13(1):57-65 [DOI:10.1080/1744666X.2016.1205486]

2. Alpsoy E. Behcet's disease: A comprehensive review with a focus on epidemiology, etiology and clinical features, and management of mucocutaneous lesions. J Dermatol. 2016;43(6):620-32. [DOI:10.1111/13468138.13381]

3. Esatoglu SN, Kutlubay Z, Ucar D, et al. Behcet's syndrome: providing integrated care. J Multidiscip Health Care2017;10:309-19. [DOI:10.2147/JMDH.S93681]

4. Khabbazi A, KarkonShayan F, Ghojazadeh M, et al. Adherence to treatment in patients with Behcet's disease. Int $J$ Rheumat Dis. 2018;21(12):2158-66. [DOI:10.1111/1756185X.13109]

5. Kilian NC, Sawalha AH. Behcet's disease in the United States: A single center descriptive and comparative study. Europ J Rheumatol. 2017;4(4):239-44. [DOI:10.5152/eurjrheum.2017.17112]

6. Mat MC, Sevim A, Fresko I, Tuzun Y. Behcet's disease as a systemic disease. ClinDermatol. 2014;32(3):435-42. [DOI:10.1016/j.clindermatol.2013.11.012] 
7. Shahriyari E, Bonyadi M, JabbarpoorBonyadi MH, Soheilian M, Yaseri M, Ebrahimiadib N. Ubiquitin associated and $\mathrm{SH} 3$ domain containing B (UBASH3B) gene association with Behcet's disease in Iranian population. Curr Eye Res. 2019;44(2):200-5.

[DOI:10.1080/02713683.2018.1524913]

8. Scherrer MAR, Rocha VB, Garcia LC. Behcet's disease: review with emphasis on dermatological aspects. Anais brasileiros de dermatologia. 2017;92(4):452-64. [DOI:10.1590/abd18064841.20177359]

9. Davari P, Rogers RS, Chan B, Nagler TH, Fazel N. Clinical features of Behcet's disease: A retrospective chart review of 26 patients. J Dermatol Treat. 2016;27(1):70-4. [DOI:10.3109/09546634.2015.1054781]

10. Kiss E, Dohan J, Nemeth J, Poor G. Behcet's disease: a rarely recognized orphan disorder. Orvosihetilap. [DOI:10.1556/OH.2013.29528]

11. Saccucci M, Di Carlo G, Bossu M, Giovarruscio F, Salucci A, Polimeni A. Autoimmune diseases and their manifestations on oral cavity: diagnosis and clinical management. J Immunol Res. 2018;2018:6061825. [DOI:10.1155/2018/6061825]

12. Munoz SA, Orden AO, Kostianovsky A, et al. The HLA-B*51 allele is strongly associated with Behcet disease in an argentinean population. ReumatolClin. [DOI:10.1016/j.reuma.2018.07.002]

13. Maldini C, Lavalley MP, Cheminant M, de Menthon M, Mahr A. Relationships of HLA-B51 or B5 genotype with Behcet's disease clinical characteristics: systematic review and metaanalyses of observational studies. Rheumatol (Oxford, England). 2012;51(5):887-900. [DOI:10.1093/rheumatology/ker428]

14. Ryu HJ, Seo MR, Choi HJ, Baek HJ. Clinical phenotypes of Korean patients with Behcet disease according to gender, age at onset, and HLA-B51. Korean J Int Med. 2018;33(5):102531. [DOI:10.3904/kjim.2016.202]

15. Hamzaoui A, Houman MH, Massouadia M, et al. Contribution of Hla-B51 in the susceptibility and specific clinical features of Behcet's disease in Tunisian patients. Europ J IntMed. 2012;23(4):347-9.

[DOI:10.1016/j.ejim.2011.12.011]

16. Demirseren DD, Ceylan GG, Akoglu G, et al. HLA-B51 subtypes in Turkish patients with Behcet's disease and their correlation with clinical manifestations. Genet Molec Res. 2014;13(3):4788-96.

[DOI:10.4238/2014.July.2.8]
17. The International Criteria for Behcet's Disease (ICBD): a collaborative study of 27 countries on the sensitivity and specificity of the new criteria. J EuropAcadDermatolVenereol 2014;28(3):338-47. [DOI:10.1111/jdv.12107]

18. Kanecki K, Nitsch-Osuch A, Gorynski P, Tarka P, Kutera A, Tyszko P. Behcet disease: a rare systemic vasculitis in Poland. Polish archives of internal medicine. 2017;127(10):652-6. [DOI:10.20452/pamw.4160]

19. Wang ZK, Shi H, Wang SD, et al. Confusing untypical intestinal Behcet's disease: Skip ulcers with severe lower gastrointestinal hemorrhage. World J GastrointestEndoscop. 2014;6(1):27-31. [DOI:10.4253/wjge.v6.i1.27]

20. Zeidan MJ, Saadoun D, Garrido M, Klatzmann D, Six A, Cacoub P. Behcet's disease physiopathology: a contemporary review. Auto Immun Highlights. 2016;7(1):4. [DOI:10.1007/s13317-016-0074-1]

21. Taylor J, Glenny AM, Walsh $\mathrm{T}$, et al. Interventions for the management of oral ulcers in Behcet's disease. Cochrane Database System Rev. 2014(9):Cd011018. [DOI:10.1002/14651858.CD011018]

22. Tunes RS, Anjos TC, Martins GB, Barreto ER, Santiago MB. Prevalence of Behcet's syndrome in patients with recurrent aphthous ulcerations in Brazil. Rheumatol Int. 2009;29(8):875-8. [DOI:10.1007/s00296-008-0787-1]

23. Lennikov A, Alekberova Z, Goloeva R, et al. Single center study on ethnic and clinical features of Behcet's disease in Moscow, Russia. ClinRheumatol. 2015;34(2):321-7. [DOI:10.1007/s10067-013-2442-9]

24. Ghembaza ME, Bouabdallah N, Lounici A. Behcet disease in Western Algeria. Medecine et santetropicales. [DOI:10.1684/mst.2017.0656]

25. Bergamo S, di Meo N, Stinco G, Bonin S, Trevisini S, Trevisan G. Adamantiades-Behcet disease at the beginning of the silk route: NorthEast Italian Experience. ActadermatovenerolCroatica : ADC. 2017;25(4):295-7.

26. Suzuki T, Horita N, Takeuchi M, et al. Clinical features of early-stage possible Behcet's disease patients with a variant-type major organ involvement in Japan. Modern Rheumatol. 2018:1-7.

27. Kim JN, Kwak SG, Choe JY, Kim SK. The prevalence of Behcet's disease in Korea: data from health insurance review and assessment service from 2011 to 2015. Clin Experiment Rheumatol. 2017;35Suppl 108(6):38-42. 
28. Sibley C, Yazici Y, Tascilar K, et al. Behcet syndrome manifestations and activity in the United States versus Turkey -- a cross-sectional cohort comparison. J Rheumatol. 2014;41(7):1379-84.

[DOI:10.3899/jrheum.131227]

29. Calamia KT, Wilson FC, Icen M, Crowson CS, Gabriel SE, Kremers HM. Epidemiology and clinical characteristics of Behcet's disease in the US: a population-based study. Arthritis Rheumatism. 2009;61(5):600-4. [DOI:10.1002/art.24423]

30. Ugurlu N, Bozkurt S, Bacanli A, AkmanKarakas A, Uzun S, Alpsoy E. The natural course and factors affecting severity of Behcet's disease: a single-center cohort of 368 patients. Rheumatol Int. 2015;35(12):2103-7. [DOI:10.1007/s00296-015-3310-5]
31. Cansu DU, Kasifoglu T, Korkmaz C. Do clinical findings of Behcet's disease vary by gender?: A single-center experience from 329 patients. Europ J Rheumatol. 2016;3(4):157-60. [DOI:10.5152/eurjrheum.2016.038]

32. Ozyurt K, Colgecen E, Baykan H. Does familial occurrence or family history of recurrent oral ulcers influence clinical characteristics of Behcet's disease? ActadermatovenerologicaCroatica : ADC. 2013;21(3):168-73.

33. Sula B, Batmaz I, Ucmak D, Yolbas I, Akdeniz $S$. Demographical and clin characteristics of Behcet's disease in Southeastern Turkey. J Clin Med Res. 2014;6(6):476-81. [DOI:10.14740/jocmr1952w]

\section{How to Cite This Article:}

Owlia F, Khodaei-ardakani Z, Soleymani saleh-abadi H. Assessment of Different Manifestations of Known Cases of Behçet's Disease. J Adv Med Biomed Res. 2020; 28 (130) :284-290

\section{Download citation:

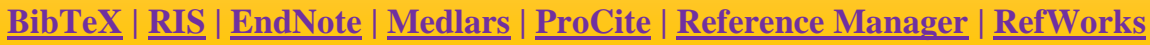

\section{Send citation to:}
Mendeley
(2) Zotero RefWorks $\underline{\text { RefWorks }}$ 